\title{
Oportunidades de melhoria na disciplina de Contabilidade Introdutória com a utilização do modelo Kano e da matriz de importância versus desempenho
}

\section{Opportunities for improvement in the subject of Introductory Accounting with the use of Kano model and importance of matrix versus performance}

\author{
Paulo Roberto da Cunha \\ Doutor em Ciências Contábeis e Administração \\ pela FURB; Professor do Programa de Pós- \\ Graduação em Ciências Contábeis -PPGCC/FURB; \\ Professor da Universidade do Estado de Santa \\ Catarina (UDESC); \\ pauloccsa@furb.br
}

\section{Silvana Anita Walter}

Doutora em Administração pela Pontifícia Universidade Católica do Paraná; Professora do Mestrado Profissional em Administração da Universidade Estadual do Oeste do Paraná UNIOESTE - Campus Cascavel; silvanaanita.walter@gmail.com

\section{Roseli Pauli Winter}

Bacharel em Ciências Contábeis pela FURB; roseli.pauli@hotmail.com
Contextus

ISSNe 2178-9258

Organização: Comitê Científico Interinstitucional Editor Científico: Marcelle Colares Oliveira Avaliação: Double Blind Review pelo SEER/OJS Revisão: Gramatical, normativa e de formatação Recebimento: 10/07/2012 Aprovação: 03/12/2013

\section{Francisco Carlos Fernandes}

Doutor em Controladoria e Contabilidade pela FEA/USP; Professor do Programa de PósGraduação em Ciências Contábeis -PPGCC/FURB; franciscofernandes@furb.br

\section{RESUMO}

O objetivo foi verificar as oportunidades de melhoria da disciplina de Contabilidade Introdutória a partir da percepção de alunos. Realizou-se um levantamento, de caráter descritivo, em uma abordagem quantitativa. Foi utilizado questionário para coleta de dados, aplicado, de forma censitária, aos alunos matriculados na disciplina de Contabilidade Introdutória nos cursos de Ciências Contábeis e de Administração de uma instituição de ensino superior do Vale do Itajaí (SC). Concluiu-se como prioridades de melhoria no curso de Ciências Contábeis, utilizando-se o Modelo Kano em conjunto com a Matriz de Importância versus Desempenho, a utilização de laboratório para a resolução de exercícios; a modernidade dos laboratórios de informática, a infraestrutura da sala de aula. No curso de Administração, foram consideradas prioridades de melhoria a oferta de atividades extracurriculares e a modernidade dos laboratórios de informática.

Palavras-chave: Contabilidade Introdutória. Atributos de qualidade. Modelo Kano. Matriz de Importância versus Desempenho. Linearidade e não-linearidade.

\begin{abstract}
This study aimed at assessing improvement opportunities of the discipline of Introductory Accounting from the students' point of view. The research is classified as descriptive and quantitative. The data collection was carried out with a survey, which questionnaire was applied to junior students enrolled in the introductory accounting discipline in the accounting and business administration courses at a university of the Itajaí River Valley, Santa Catarina State, Brazil. We used Kano Model and the Importance-performance Matrix. The study concluded the priorities for improvement for accounting students are the use of IT laboratory for problem solving and the quality (up to date) infrastructure of computer labs and classroom. Students of the business administration considered extracurricular activities and modernity of computer labs as the main opportunities of improvement.
\end{abstract}

Keywords: Introductory accounting. Quality atributes. Kano Model. Matrix Performance vs. Importance. Linear and nonlinear. 


\section{INTRODUÇÃO}

$\mathrm{Na}$ busca por melhores condições de ensino superior, tornou-se fundamental a definição de uma política de gestão da qualidade que oriente as instituições de ensino superior (IES) (PELEIAS, 2006). Para tal, é essencial avaliar os principais atributos da qualidade no ensino superior e acompanhar constantemente a evolução das necessidades dos consumidores (TONTINI, 1996). Assim, estudos procuram avaliar a qualidade percebida e a satisfação de estudantes com seus cursos e instituições de ensino superior. Silveira, Appio e Domingues (2008) destacam que os estudos sobre a qualidade no ensino superior poderiam avaliar também as disciplinas dos cursos. Isso é pouco explorado pela literatura e poderia auxiliar as instituições no processo de implantação de sistemas de avaliação de disciplinas, visto que muitas vezes a mesma disciplina é ofertada para diferentes cursos.

A disciplina de Contabilidade Introdutória (pode ter outra nomenclatura de acordo com a IES), por exemplo, além de ser oferecida para o curso de Contabilidade, também o é para o de Administração. Essa disciplina oferece subsídios importantes para a compreensão da prática contábil, fornecendo ferramentas para a tomada de decisão nas organizações tanto para os futuros contadores quanto para administradores. Desse modo, tornase pertinente identificar suas oportunidades de melhoria de acordo com a percepção de quem recebe o serviço educacional, os discentes. Para tal, a questão que norteia esta pesquisa é: Quais as oportunidades de melhoria resultantes da percepção de discentes de uma IES para a disciplina de contabilidade introdutória? Dessa forma, este estudo objetiva verificar as oportunidades de melhoria da disciplina de Contabilidade Introdutória nos cursos de Ciências Contábeis e de Administração.

Este artigo está estruturado em mais cinco seções além desta introdução. Na próxima seção, apresenta-se uma breve revisão de literatura de estudos sobre qualidade e satisfação no ensino superior. Na terceira seção, destacam-se os modelos que serão utilizados para mensurar as oportunidades de melhoria da disciplina analisada, compreendendo a Matriz de Importância versus Desempenho e o Modelo Kano de Qualidade Atrativa e Obrigatória. Na quarta seção, descrevemse os procedimentos metodológicos empregados. Na quinta seção, exibem-se os resultados obtidos divididos entre os dois cursos verificados e faz-se sua análise com base nos modelos de mensuração empregados. Por fim, na seção seguinte, expõem-se as considerações finais do 
artigo, incluindo conclusão, limitações da pesquisa e sugestões para futuros estudos.

\section{AVALIAÇÃO DA QUALIDADE E} DA SATISFAÇÃO NO ENSINO SUPERIOR

Nesta seção, apresentam-se alguns estudos sobre qualidade percebida e satisfação de estudantes com seu curso ou instituição de ensino superior. Assim, este estudo poderá verificar se as principais variáveis citadas pelos autores também podem ser aplicadas na avaliação de disciplinas por meio do exemplo da disciplina de Contabilidade Introdutória.

No que se refere à qualidade em IES, Owlia e Aspinwall (1996) propõem uma correspondência entre as dimensões de avaliação da qualidade dos serviços do SERVQUAL (PARASURAMAN et al., 1988) e os fatores da qualidade no ensino superior. Os resultados desse estudo sugerem seis dimensões por meio das quais é possível avaliar a qualidade percebida no ensino superior. São elas: a) tangíveis: equipamentos e instalações suficientes e atualizados, ambiente agradável e instalações de apoio (dormitórios, desportos, entre outras); b) competência: formação, atualização, conhecimentos práticos, experiência, capacidade de ensino e quantidade de professores; c) atitude: compreensão das necessidades dos alunos, vontade de ajudar, disponibilidade de acesso e de tempo para orientação e simpatia; d) conteúdo: aspectos relacionados à relevância do conteúdo para os futuros empregos dos alunos, formação para trabalho em equipe $\mathrm{e}$ multidisciplinaridade dos conteúdos e cursos; e) prestação: métodos de ensino empregados, forma de apresentação do conteúdo e das aulas, justiça nas avaliações, feedback aos estudantes; f) confiabilidade: atribuição de diplomas válidos, cumprimento de promessas e gestão de queixas.

Alves e Raposo (1999) utilizaram as dimensões encontradas nos estudos de Owlia e Aspinwall (1996) para uma análise dos pontos fortes e fracos da universidade. Foram avaliados: aspectos gerais da universidade; biblioteca; serviços de laboratório e informática, serviços de ação social, acadêmicos e de docência; conteúdo dos cursos; ligações da universidade com o exterior. Essas dimensões foram analisadas em três categorias: serviços centrais, complementares e periféricos. A referida pesquisa identificou como principais dimensões da qualidade percebida: serviços acadêmicos; serviços de laboratório e informática; conteúdo dos cursos; serviços de docência; serviços de ação social.

Alves (2000) continuou estudando as dimensões da qualidade percebida na universidade a partir de Owlia e Aspinwall 
(1996), reunindo as variáveis em dois grupos: as relacionadas ao serviço central, isto é, relacionadas diretamente ao ensino, e as relacionadas ao serviço periférico, explorando o modo como os serviços são prestados. As dimensões que apresentaram maior impacto na qualidade percebida, para todos os grupos pesquisados, foram: a) docência: fatores relacionados à capacidade dos professores em sala de aula, métodos de ensino e avaliação utilizados, relacionamento entre professor e alunos, acessibilidade aos docentes e existência de bibliografia básica; b) instalações: variáveis relacionadas à modernidade e à limpeza das instalações; c) atividades extracurriculares: variáveis relacionadas à existência de atividades desportivas, atividades culturais e associações de alunos; d) empregabilidade potencial do curso: associada ao conteúdo atualizado do curso e à diversidade de saídas profissionais oferecidas pelo curso; e) prestabilidade dos serviços gerais.

Marks (2000) desenvolveu um instrumento de avaliação ao qual incorporou componentes de um ensino efetivo e os relacionou a duas medidas gerais: satisfação geral com o curso e com o professor. A pesquisa foi aplicada a estudantes que participavam de cursos de administração de curta duração, ministrados por um único professor. Os resultados identificaram, como componentes principais de ensino efetivo percebido, os seguintes agrupamentos: organização (do curso e das aulas); carga de trabalho/nível de dificuldade; expectativa/justiça nas avaliações; relacionamento com o professor; aprendizagem percebida. Tendo a satisfação geral com o curso como medida global, Marks (2000) concluiu que: relacionamento com o professor tem impacto na percepção de aprendizagem percebida e nos níveis de expectativa em relação à justiça das avaliações; quanto maior a carga de trabalho e o nível de dificuldade menor a percepção sobre justiça nas avaliações; organização do curso tem impacto direto na percepção da aprendizagem percebida e na percepção da justiça nas avaliações; justiça das avaliações e aprendizagem percebida impactam a satisfação geral como medida global, sendo a aprendizagem percebida o fator mais importante. No modelo que tem a satisfação com o professor como medida global, os resultados permaneceram iguais aos do modelo da satisfação geral, exceto: aprendizagem percebida, que impactava a satisfação com o curso, deixa de ter impacto na satisfação com professor; relacionamento com o professor $\mathrm{e}$ organização, que não impactava a satisfação com o curso, passa a impactar a satisfação com o professor. Para Marks (2000), conteúdo apropriado e nível de exigência mais elevado geram 
aprendizagem, embora não tragam satisfação; porém, o nível de dificuldade e a carga de trabalho só afetam a satisfação com o professor quando os estudantes sentem que a exigência feita é injusta.

Investigando a satisfação de alunos, Walter, Tontini e Domingues (2005) buscaram identificar oportunidades de melhoria em um curso de graduação em Administração. Avaliaram vinte atributos agrupados em seis dimensões: atendimento nas secretarias, capacitação dos professores, métodos de ensino, atitude dos funcionários, conteúdo das disciplinas e infraestrutura. As principais prioridades de melhoria identificadas foram: quantidade de vagas no estacionamento, agilidade do laboratório de impressão, modernidade dos laboratórios de informática e relação entre teoria e prática nas disciplinas. Os autores concluíram que aspectos didáticopedagógicos (métodos de ensino e capacitação dos professores) são os que mais influenciam a satisfação geral e a avaliação da contribuição do curso para o desempenho profissional. Outra conclusão do estudo é que quanto maior o nível de exigência dos professores menor a satisfação dos alunos com o curso.

\section{MODELOS DE MENSURAÇÃO DAS OPORTUNIDADES DE MELHORIA}

Nesta seção, destacam-se a Matriz de Importância versus Desempenho e o
Modelo Kano de Qualidade Atrativa e Obrigatória, os quais serão empregados para analisar as oportunidades de melhoria da disciplina de Contabilidade Introdutória.

A análise de importância versus desempenho é uma técnica de identificação de oportunidades de melhoria introduzida originalmente por Martilla e James (1977). Essa técnica de análise permite à organização ter uma visão sobre quais atributos de seu produto ou serviço devem ser melhorados para proporcionar satisfação aos usuários (WALTER, 2006).

A importância é atribuída por meio de uma escala direta (Ex: 1 a 5) ou análise de regressão, em que a importância é dada pelo coeficiente de uma regressão linear entre o desempenho do atributo e a satisfação geral com o serviço. $\mathrm{O}$ desempenho é atribuído por meio de escala direta (Ex: 1 a 10) ou de maneira relativa à concorrência ou ao desempenho esperado (Ex: Muito Pior, Pior, Igual, Melhor, Muito Melhor) (GARVER, 2003).

Matzler et al. (2004, p. 272) expõem que "[...] os dados de pesquisas sobre satisfação são utilizados para construir uma matriz bi-dimensional, na qual é retratada a importância ao longo do eixo-x e desempenho (satisfação) ao longo do y". Essa matriz pode ser organizada em quatro quadrantes. No Quadrante I, estão os atributos que representarão alta importância e alto desempenho, 
demonstrando possíveis vantagens competitivas. No Quadrante II, estão os atributos que representarão alta importância e baixo desempenho, demonstrando possíveis desvantagens competitivas, que deverão receber investimentos imediatos para sua melhoria. No Quadrante III, encontram-se os atributos que representarão baixa importância e baixo desempenho, exemplificando que não há necessidade alguma de realizar ações de melhoria. No Quadrante IV estão os atributos que representarão baixa importância e alto desempenho, mostrando que a organização está desperdiçando melhorias que poderia ser mais bem aproveitado em outros itens ou na melhoria de outro atributo (TONTINI; SILVEIRA, 2005).

A Matriz de Importância versus Desempenho tem como suposição a separação entre o desempenho e a importância. No entanto, Matzler et al. (2004) destacam que a importância pode variar conforme o desempenho. Outro pressuposto é que há linearidade entre o desempenho e a satisfação. Entretanto, Zanchett (2009) aponta que alguns tipos de atributos não proporcionam aumento na satisfação do consumidor na mesma proporção que o aumento de desempenho, evidenciando, assim, uma relação nãolinear entre desempenho e satisfação geral. Assim sendo, esses pressupostos passam a constituir uma limitação desse método, visto que pode levar a decisões equivocadas de melhoria. Essas limitações podem ser minimizadas por meio da aplicação em conjunto com uma metodologia não-linear e que não está embasada na relação entre desempenho e importância, como o Modelo Kano.

O Modelo Kano de Qualidade Atrativa e Obrigatória, introduzido originariamente por Kano (1984), é uma técnica gerencial para analisar quais atributos deveriam ser incorporados a um produto ou serviço.

Esse modelo traz uma perspectiva diferente para a análise de oportunidades de melhoria, pois leva em consideração a relação não-linear e assimétrica entre desempenho e satisfação, influenciando na satisfação do cliente por meio de três tipos de atributos de produtos ou serviços: obrigatórios, unidimensionais e atrativos (TONTINI; SILVEIRA, 2005). O Quadro 1 sintetiza cada um desses tipos de atributos: 
Quadro 1 - Atributos de produtos e serviços

\begin{tabular}{|c|c|c|}
\hline \multicolumn{2}{|c|}{ Tipos de atributos de produtos e serviços } \\
\hline $\begin{array}{c}\text { Atributos } \\
\text { obrigatórios }\end{array}$ & $\begin{array}{c}\text { São os critérios básicos de um produto. São exigências mínimas que, se não estiverem } \\
\text { presentes ou não atingirem um nível de desempenho suficiente, provocarão insatisfação nos } \\
\text { clientes. Por outro lado, se esses atributos estiverem presentes ou forem suficientes, não se } \\
\text { traduzem em satisfação. De fato, os clientes veem esses atributos como pré-requisitos do } \\
\text { produto ou serviço. }\end{array}$ \\
\hline $\begin{array}{c}\text { Atributos } \\
\text { atrativos }\end{array}$ & $\begin{array}{c}\text { São chaves para a satisfação do cliente. O atendimento desses atributos traz uma satisfação } \\
\text { mais que proporcional, porém eles não trazem insatisfação se não forem atendidos. São } \\
\text { atributos nem sempre expressos explicitamente e nem esperados pelo cliente. }\end{array}$ \\
\hline $\begin{array}{c}\text { Atributos } \\
\text { unidimensionais }\end{array}$ & A satisfação do cliente é proporcional ao nível de desempenho desses atributos - quanto \\
maior o nível maior será a satisfação do cliente, e vice-versa.
\end{tabular}

Fonte: Adaptado de Tontini (1996).

Os atributos obrigatórios geralmente não são exigidos explicitamente pelos clientes, pois eles os consideram como inerentes. Os atributos atrativos não são nem expressos explicitamente e nem esperados pelo cliente. E os atributos unidimensionais geralmente são exigidos explicitamente pelos clientes (TONTINI, 2003).

Além desses três tipos de atributos, outros dois podem ser identificados: os neutros e os reversos. Atributos neutros são aqueles cuja presença é indiferente o cliente, ou seja, se estiverem presentes não trarão satisfação e se não estiverem presentes não trarão insatisfação. Sua presença ou suficiência e sua ausência ou insuficiência não alteram os resultados. Esses atributos nunca ou raramente são utilizados pelos clientes, que também podem desconhecer sua utilização. Atributos reversos são aqueles que existem para satisfazer o cliente, mas na realidade deixam o cliente insatisfeito, ou seja, são aqueles cuja presença ou suficiência provocam insatisfação (TONTINI, 2003).

A classificação dos atributos do Modelo Kano é identificada por meio de um questionário que contenha duas perguntas para cada característica do produto e/ou serviço: uma na qual um atributo específico está presente ou tem desempenho suficiente (questão funcional) e outra negando a anterior (questão disfuncional) (TONTINI, 2003).

Os coeficientes de satisfação podem ser demonstrados em um gráfico de dispersão, dividindo-se em quatro quadrantes, visualizando-se a classificação de cada atributo em atrativo, unidimensional, neutro e obrigatório. A posição das linhas que separam os quadrantes varia de acordo com o tipo de produto ou serviço analisado e de acordo com o objetivo da demonstração do resultado. Se uma percentagem de $50 \%$ de usuários insatisfeitos for considerada muito alta para a separação entre um atributo 
atrativo e unidimensional, a linha de separação desses quadrantes pode ser ajustada para $-0,30$. O mesmo pode ocorrer para o índice de satisfação (TONTINI, 2003).

Ao se empregar o Modelo de Kano, existe a possibilidade de fazer uso do Coeficiente de Satisfação do Cliente (CSC). Esse coeficiente indica a porcentagem de clientes que ficam satisfeitos com a existência ou suficiência de um atributo, e a porcentagem de clientes que ficam insatisfeitos com a ausência ou insuficiência (BERGER et al., 1993). O grau de satisfação do cliente é determinado por meio de dois índices: coeficiente de satisfação (CS) e coeficiente de insatisfação (CI) (TONTINI, 2003).

\section{MÉTODOS E PROCEDIMENTOS DA PESQUISA}

A presente pesquisa caracteriza-se, quanto aos objetivos, como descritiva. Quanto aos procedimentos, como levantamento, e quanto à abordagem do problema, ela enquadra-se como quantitativa. A população foi definida de forma intencional, por conveniência, em alinhamento com o objeto de estudo, e os sujeitos foram alunos que cursaram a disciplina de contabilidade nos cursos de Administração e Ciências Contábeis de uma IES de Blumenau-SC, perfazendo o total de 128 alunos, em cinco turmas: duas de Ciências Contábeis e três de Administração. A pesquisa caracterizou-se como censitária, pois coleta informações de todo o universo pesquisado (RAUPP; BEUREN, 2004), sendo aplicada a todos os presentes em sala de aula no momento da coleta dos dados, ocorrida no mês de maio de 2010, totalizando 101 respondentes.

Os dados foram coletados por meio de um questionário estruturado, adaptado de Walter, Tontini e Domingues (2005) e complementado com atributos identificados por meio de um grupo focal, visando adaptá-lo ao contexto. Em relação à entrevista com grupos de foco, foi realizado o levantamento dos atributos por meio de 15 alunos voluntários do segundo semestre do curso noturno de Ciências Contábeis, os quais já haviam passado pela disciplina de Contabilidade Introdutória. O roteiro de entrevistas utilizado continha 17 perguntas abrangendo atributos de cinco categorias: capacitação do professor, métodos de ensino, atitude, conteúdo e infraestrutura. Já o questionário empregado contemplou 23 atributos agrupados nas cinco categorias, conforme se demonstra no Quadro 2. 
Quadro 2 - Categorias de atributos utilizados na pesquisa

\begin{tabular}{|c|c|c|}
\hline Categorias & Atributos & Fonte \\
\hline \multirow{3}{*}{$\begin{array}{l}\text { Capacitação } \\
\text { dos professores }\end{array}$} & Atualização do professor & \multirow{3}{*}{$\begin{array}{l}\text { Alves (2000), Alves e Raposo } \\
\text { (1999), Walter, Tontini e } \\
\text { Domingues (2005) }\end{array}$} \\
\hline & Titulação do professor & \\
\hline & Experiência prática sobre o conteúdo ministrado & \\
\hline \multirow{7}{*}{$\begin{array}{l}\text { Métodos de } \\
\text { ensino }\end{array}$} & Relação entre teoria e prática na disciplina & $\begin{array}{l}\text { Owlia e Aspinwall (1996) e } \\
\text { Walter, Tontini e Domingues } \\
(2005)\end{array}$ \\
\hline & Aplicação de diversos exercícios & \multirow{3}{*}{ Grupo de foco } \\
\hline & $\begin{array}{l}\text { Aplicação de exercícios que envolvam indústria, comércio e } \\
\text { serviços }\end{array}$ & \\
\hline & $\begin{array}{l}\text { Utilização de laboratório para resolução de exercícios em } \\
\text { planilhas eletrônicas }\end{array}$ & \\
\hline & $\begin{array}{l}\text { Quantidade de materiais disponíveis no ambiente virtual de } \\
\text { aprendizagem }\end{array}$ & \multirow[t]{3}{*}{$\begin{array}{l}\text { Marks (2000), Walter, Tontini e } \\
\text { Domingues (2005) }\end{array}$} \\
\hline & Critérios de avaliação usados na disciplina & \\
\hline & Nível de exigência do professor & \\
\hline \multirow{4}{*}{ Atitude } & Relacionamento do professor com os alunos & \multirow{4}{*}{$\begin{array}{l}\text { Owlia e Aspinwall (1996), Marks } \\
\text { (2000), Walter, Tontini e } \\
\text { Domingues (2005) }\end{array}$} \\
\hline & Atendimento do professor em horários extraclasse & \\
\hline & Disposição do professor para a preparação das aulas & \\
\hline & Disposição do professor para a condução das aulas & \\
\hline \multirow{6}{*}{ Conteúdo } & Contribuição da disciplina para o desempenho profissional & \multirow{6}{*}{$\begin{array}{l}\text { Alves (2000), Alves e Raposo } \\
\text { (1999), Walter, Tontini e } \\
\text { Domingues (2005) }\end{array}$} \\
\hline & Pertinência dos assuntos para a disciplina & \\
\hline & $\begin{array}{l}\text { Oferta de atividades extracurriculares (Ex.: visitas à empresa, } \\
\text { estudo de campo e outras) }\end{array}$ & \\
\hline & Atualização do conteúdo & \\
\hline & Inter-relação com as demais disciplinas do curso & \\
\hline & Carga horária da disciplina & \\
\hline \multirow{3}{*}{ Infraestrutura } & $\begin{array}{l}\text { Quantidade de títulos da disciplina de contabilidade } \\
\text { introdutória na biblioteca }\end{array}$ & \multirow{3}{*}{$\begin{array}{l}\text { Owlia e Aspinwall (1996), Walter, } \\
\text { Tontini e Domingues (2005) }\end{array}$} \\
\hline & $\begin{array}{l}\text { Contribuição da modernidade dos laboratórios de informática } \\
\text { para a disciplina }\end{array}$ & \\
\hline & $\begin{array}{l}\text { Infraestrutura da sala de aula (tamanho, conforto, } \\
\text { ventiladores e/ou ar-condicionado, equipamentos e outros } \\
\text { itens) }\end{array}$ & \\
\hline
\end{tabular}

Fonte: Adaptado de Walter, Tontini e Domingues (2005) e complementado por meio de Grupo de Foco.

\section{O questionário foi composto por} quatro etapas. A primeira identificou atributos segundo o Modelo Kano. Nesse sentido, sempre havia duas perguntas, descrevendo respectivamente uma situação de aumento e outra de diminuição no desempenho de cada atributo. Para cada pergunta $o$ respondente indicou sua expectativa de satisfação ou insatisfação em relação às situações mencionadas, numa escala variando de extremamente insatisfeito (-5) a extremamente satisfeito
(5). $\mathrm{Na}$ segunda parte, mensurou-se a satisfação geral atual com a disciplina de Contabilidade Introdutória e o grau de satisfação existente em relação ao nível de desempenho atual encontrado nos atributos com a mesma escala. Na terceira etapa, verificou-se o grau de importância para cada um dos atributos em uma escala de importância de 1 a 5 . Na última etapa, pesquisaram-se dados pessoais e de frequência de utilização dos atributos por meio de perguntas estruturadas. Os 
resultados obtidos são apresentados em gráficos de dispersão gerados com $\mathrm{o}$ auxílio de uma planilha eletrônica.

Para a divisão dos quadrantes da Matriz de Importância versus Desempenho, optou-se por estabelecer a linha divisória de importância em 3 (importante na escala do questionário) e a linha da satisfação atual pela média geral da satisfação atual dos atributos pesquisados. Já para o gráfico de dispersão do índice de satisfação do cliente conforme o Modelo Kano, estabeleceu-se a divisão dos quadrantes pela média geral de satisfação dos atributos.

\section{DESCRIÇÃO E ANÁLISE DOS DADOS}

Nesta seção, são analisados os dados na perspectiva da Matriz de Importância versus Desempenho e do Modelo Kano de Qualidade Atrativa e Obrigatória, analisando primeiramente o curso de Ciências Contábeis e depois o curso de Administração. Na Figura 1, apresenta-se o gráfico de dispersão para a análise da Matriz de Importância versus Desempenho para os atributos pesquisados no curso de Ciências Contábeis.

Figura 1 - Gráfico da Matriz de Importância versus Desempenho do curso de Ciências Contábeis

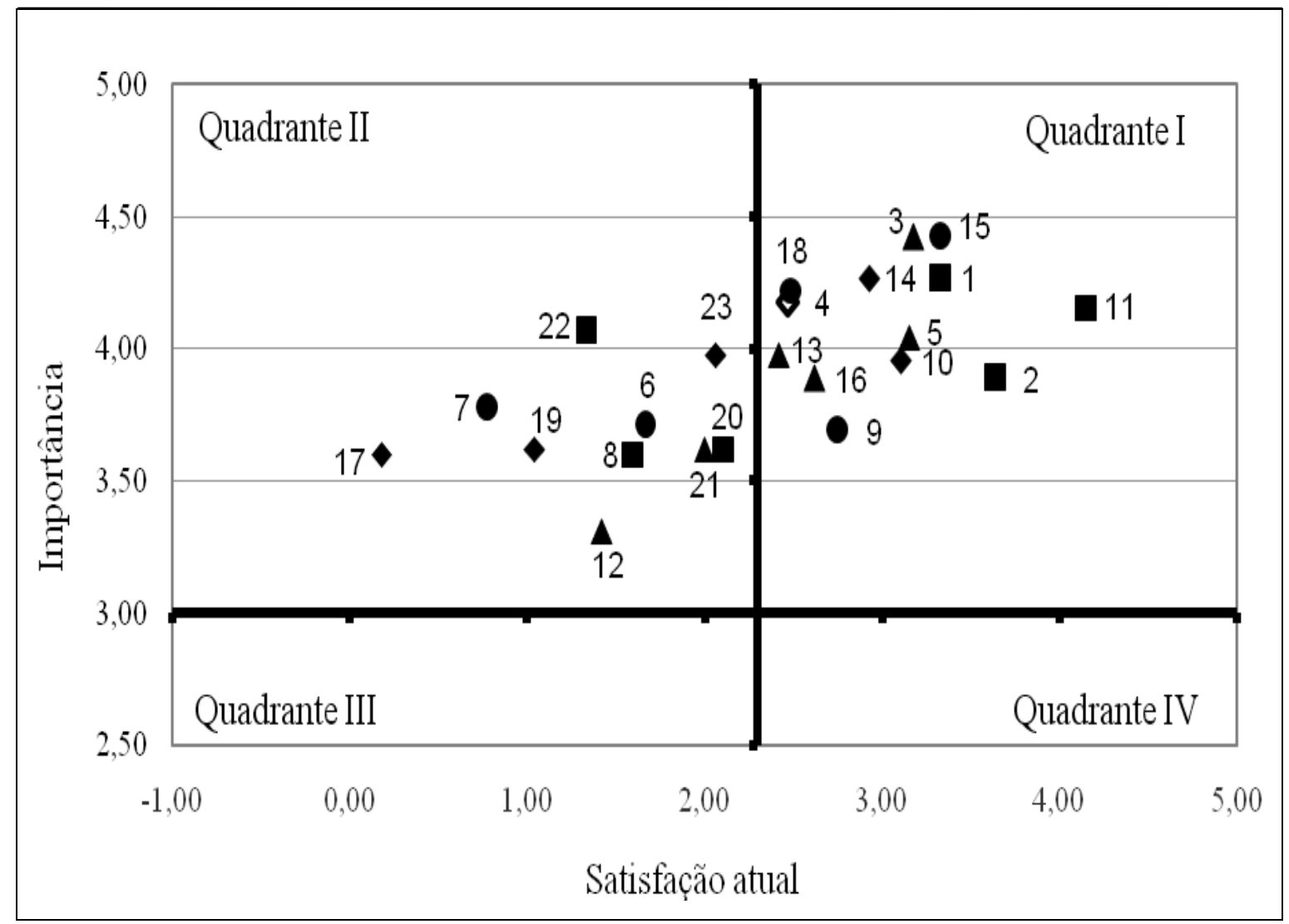




\begin{tabular}{|l|l|l|l|}
\hline \multicolumn{2}{|l}{ Legenda Figura 1: } & 13 & Disposição do professor para preparar as aulas \\
\hline 1 & Atualização do professor & 14 & Disposição do professor para conduzir as aulas \\
\hline 2 & Titulação do professor & 15 & $\begin{array}{l}\text { Contribuição da disciplina para o desempenho } \\
\text { profissional }\end{array}$ \\
\hline 3 & $\begin{array}{l}\text { Experiência prática do professor no assunto } \\
\text { ministrado }\end{array}$ & 16 & Pertinência dos assuntos para a disciplina \\
\hline 4 & Relação entre teoria e prática & 17 & Oferta de atividades extracurriculares \\
\hline 5 & Quantidade de exercícios & 18 & Atualização do conteúdo \\
\hline 6 & $\begin{array}{l}\text { Aplicação de exercícios que envolvam indústria, } \\
\text { comércio e serviços }\end{array}$ & 19 & $\begin{array}{l}\text { Apresentação de inter-relação com as demais } \\
\text { disciplinas do curso }\end{array}$ \\
\hline 7 & $\begin{array}{l}\text { Utilização de laboratório para a resolução de } \\
\text { exercícios }\end{array}$ & 20 & Carga horária da disciplina \\
\hline 8 & $\begin{array}{l}\text { Quantidade de materiais disponíveis no ambiente } \\
\text { virtual de aprendizagem }\end{array}$ & 21 & $\begin{array}{l}\text { Quantidade de títulos da disciplina de } \\
\text { contabilidade introdutória na biblioteca }\end{array}$ \\
\hline 9 & Critérios de avaliação usados na disciplina & 22 & Modernidade dos laboratórios de informática \\
\hline 10 & Nível de exigência do professor & 23 & Infraestrutura da sala de aula \\
\hline 11 & $\begin{array}{l}\text { Relacionamento do professor com os alunos em } \\
\text { sala de aula }\end{array}$ & \begin{tabular}{l} 
Atendimento do professor em horários extraclasse \\
\hline 12
\end{tabular} & \\
\hline
\end{tabular}

Fonte: os autores.

No Quadrante I da Figura 1, encontram-se os atributos de alta importância e de alta satisfação, ou seja, os pontos fortes da disciplina de Contabilidade Introdutória no curso de Ciências Contábeis. Nesse quadrante, localizaram-se os seguintes atributos: relacionamento do professor com os alunos em sala de aula (11), titulação do professor (2), contribuição da disciplina para o desempenho profissional (15), atualização do professor (1), quantidade de exercícios (5), nível de exigência do professor (10), experiência prática do professor no assunto ministrado (3), disposição do professor para conduzir as aulas (14), critérios de avaliação usados na disciplina (9), pertinência dos assuntos para a disciplina (16), atualização do conteúdo (18), relação entre teoria e prática (4) e disposição do professor para preparar as aulas (13). Ressalta-se que o atributo relacionamento do professor com os alunos em sala de aula (11) se destaca como o de maior satisfação. Dos 23 atributos analisados, 13 deles se classificaram no Quadrante I, no qual foram distribuídos $100 \%$ dos atributos da categoria Capacitação do Professor, 50\% dos atributos dos Métodos de Ensino, $75 \%$ dos atributos de Atitude e 50\% da categoria Conteúdo. Destaca-se que no Quadrante I não se classificou nenhum item da categoria Infraestrutura. 
No Quadrante II, encontram-se os atributos considerados de alta importância e que estão com o nível de satisfação abaixo da média. Esses são os atributos que, segundo a Matriz de Importância versus Desempenho, merecem melhorias: infraestrutura da sala de aula (23), carga horária da disciplina (20), quantidade de títulos da disciplina de Contabilidade Introdutória na biblioteca (21), modernidade dos laboratórios de informática (22), aplicação de exercícios que envolvam indústria, comércio $\mathrm{e}$ serviços (6), quantidade de materiais disponíveis no ambiente virtual de aprendizagem (8), atendimento do professor em horários extraclasse (12), apresentação de inter-relação com as demais disciplinas do curso (19), utilização de laboratório para resolução de exercícios (7) e oferta de atividades extracurriculares (17). O atributo oferta de atividades extracurriculares (17) é o que se apresenta com a satisfação atual mais baixa e o referente à modernidade dos laboratórios de informática (22), com a importância mais alta.

A categoria de Infraestrutura apresentou-se $100 \%$ no Quadrante II, ou seja, os alunos consideraram que os atributos dessa categoria estão abaixo da média. Com 50\%, as categorias métodos de ensino e conteúdo também foram contempladas nesse quadrante. A atitude apresentou-se neste quadrante com um percentual de $25 \%$.

Nos Quadrantes III (baixa importância e baixo desempenho) e IV (baixa importância e alto desempenho) não foram encontrados atributos, conforme demonstrado na Figura 1, o que demonstra que nenhum dos atributos pesquisados são considerados pelos alunos do curso de Ciências Contábeis como de baixa importância na análise da disciplina da Contabilidade Introdutória.

Na Figura 2, demonstra-se o gráfico de dispersão para a análise do índice de satisfação dos alunos conforme o Modelo Kano de Qualidade Atrativa e Obrigatória. 
Figura 2 - Gráfico do índice de satisfação dos alunos do curso de Ciências Contábeis

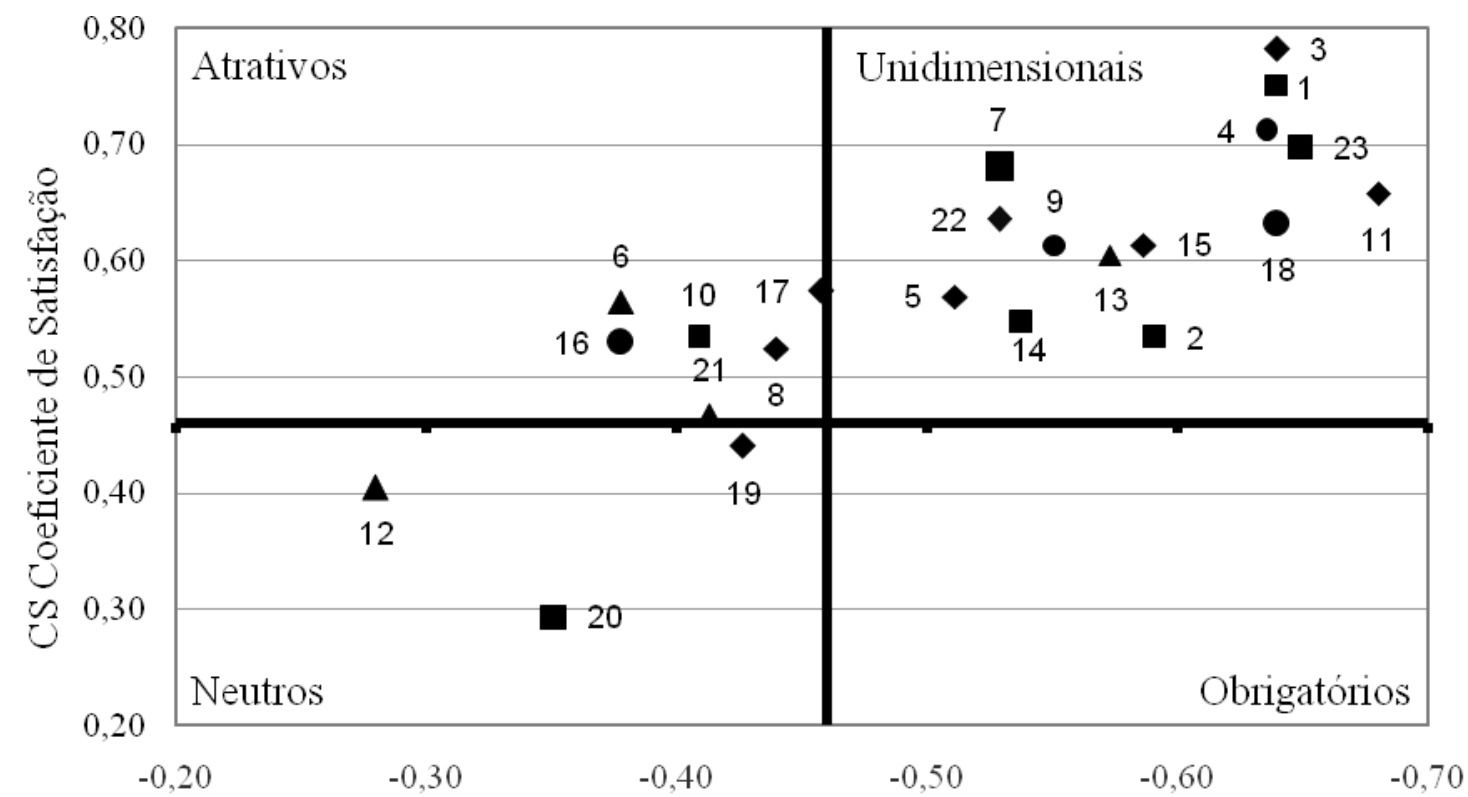

CI Coeficiente de Insatisfação

\begin{tabular}{|c|l|c|l|}
\hline \multicolumn{2}{|l|}{ Legenda: } & 13 & Disposição do professor para preparar as aulas \\
\hline 1 & Atualização do professor & 14 & Disposição do professor para conduzir as aulas \\
\hline 2 & Titulação do professor & 15 & $\begin{array}{l}\text { Contribuição da disciplina para o desempenho } \\
\text { profissional }\end{array}$ \\
\hline 3 & $\begin{array}{l}\text { Experiência prática do professor no assunto } \\
\text { ministrado }\end{array}$ & 16 & Pertinência dos assuntos para a disciplina \\
\hline 5 & Relação entre teoria e prática & 17 & Oferta de atividades extracurriculares \\
\hline 6 & $\begin{array}{l}\text { Aplicação de exercícios que envolvam indústria, } \\
\text { comércio e serviços }\end{array}$ & 18 & Atualização do conteúdo \\
\hline 7 & $\begin{array}{l}\text { Utilização de laboratório para resolução de } \\
\text { exercícios }\end{array}$ & 19 & $\begin{array}{l}\text { Apresentação de inter-relação com as demais } \\
\text { disciplinas do curso }\end{array}$ \\
\hline 8 & $\begin{array}{l}\text { Quantidade de materiais disponíveis no ambiente } \\
\text { virtual de aprendizagem }\end{array}$ & 20 & Carga horária da disciplina \\
\hline 9 & $\begin{array}{l}\text { Critérios de avaliação usados na disciplina } \\
\text { Cítulos da disciplina de }\end{array}$ \\
\hline 10 & Nível de exigência do professor 21 & $\begin{array}{l}\text { Quantidade de } \\
\text { contabilidade introdutória na biblioteca }\end{array}$ \\
\hline 11 & $\begin{array}{l}\text { Relacionamento do professor com os alunos em } \\
\text { sala de aula }\end{array}$ & 22 & Modernidade dos laboratórios de informática \\
\hline 12 & $\begin{array}{l}\text { Atendimento do professor em horários } \\
\text { extraclasse }\end{array}$ & Infraestrutura da sala de aula \\
\hline
\end{tabular}

Fonte: os autores.

Por meio da Figura 2, observa-se que três atributos podem ser considerados como neutros, ou seja, de desempenho indiferente para os alunos: apresentação de inter-relação com as demais disciplinas do curso (19), carga horária da disciplina (20) e atendimento do professor em horários extraclasse (12). Destaca-se que se apresentou como neutro, de acordo com a percepção dos alunos de Ciências Contábeis, o atributo apresentação de interrelação com as demais disciplinas do curso (19), ainda que se apresente próximo da linha divisória do quadrante atrativo. 
Contabilidade Introdutória é essencial e pré-requisito para as outras disciplinas de contabilidade, além de sua ligação com as demais disciplinas do curso poder ocorrer em diversos momentos no transcorrer da formação do contador.

Os atributos classificados como unidimensionais (satisfação é proporcional ao nível de desempenho) são: relacionamento do professor com os alunos (11), experiência prática sobre o conteúdo ministrado (3), atualização do professor (1), infraestrutura da sala de aula (23), relação entre teoria e prática (4), atualização do conteúdo (18), contribuição da disciplina para o desempenho profissional (15), titulação do professor (2), disposição do professor para preparar as aulas (13), critérios de avaliação (9), utilização de laboratório para resolução de exercícios em planilhas eletrônicas (7), contribuição da modernidade dos laboratórios de informática para a disciplina (22), disposição do professor para conduzir as aulas (14) e quantidade de exercícios aplicados (5).

Observam-se ainda os atributos considerados como atrativos, os quais proporcionam uma satisfação mais que proporcional quando estão com desempenho acima da média, mas não causam insatisfação quando estão com desempenho abaixo da média. São eles: quantidade de materiais disponíveis no ambiente virtual de aprendizagem (8), nível de exigência do professor (10), aplicação de exercícios que envolvam indústria, comércio e serviços (6) e pertinência dos assuntos para a disciplina (16). Tem-se ainda a oferta de atividades extracurriculares (17), que se apresentou muito próximo à linha divisória com os atributos unidimensionais, e a quantidade de títulos da disciplina de contabilidade introdutória na biblioteca (21), que se localizou bem próximo à linha divisória com os atributos neutros.

Por meio da análise conjunta dos resultados obtidos para a Matriz de Importância versus Desempenho e para o Modelo Kano, podem-se definir as prioridades de melhoria para a disciplina no curso de Ciências Contábeis. Dos atributos identificados como importantes e abaixo da média de satisfação na Matriz de Importância versus Desempenho, que seriam prioridades de melhoria se considerado esse método isoladamente, os atributos atendimento do professor em horários extraclasse (12), apresentação de inter-relação com as demais disciplinas do curso (19) e carga horária da disciplina (20) foram identificados como neutros, ou seja, não causam satisfação nem insatisfação se tiverem seus desempenhos 
alterados, não sendo, portanto, prioridades de melhoria.

Nesse sentido, as prioridades de melhoria passam a ser os atributos unidimensionais com alta importância e abaixo da média de satisfação na Matriz de Importância versus Desempenho, visto que atualmente estão causando insatisfação, sendo eles: utilização de laboratório para resolução de exercícios (7), modernidade dos laboratórios de informática (22) e infraestrutura da sala de aula (23). Percebeu-se que, até o momento da aplicação dos questionários, os alunos ainda não tiveram aula com a utilização dos laboratórios de informática, o que pode ter influenciado na resposta dos mesmos.

Em uma segunda etapa de melhorias, pode-se investir nos atributos atrativos que estão abaixo da média de satisfação, visto que sua melhoria trará satisfação mais que proporcional, apesar do baixo desempenho não causar insatisfação. Eles foram identificados como: quantidade de materiais disponíveis no ambiente virtual de aprendizagem (8) e aplicação de exercícios que envolvam indústria, comércio e serviços (6).

Nota-se que os atributos prioritários para melhoria $(7,22,23,8$ e 6$)$ compõem as categorias infraestrutura e métodos de ensino. A infraestrutura é ressaltada no estudo de Owlia e Aspiwall (1996) como importante para a percepção da qualidade de uma IES. Além disso, no estudo de Walter, Tontini e Domingues (2005), a modernidade dos laboratórios de informática também figurou entre as prioridades de melhoria. Já a categoria métodos de ensino é apontada nos estudos de Owlia e Aspinwall (1996), Marks (2000) e Walter, Tontini e Domingues (2005), bem como os atributos utilização do laboratório para resolução de exercícios e aplicação de exercícios que envolvam indústria, comércio e serviços foram obtidos por meio do grupo de foco realizado com estudantes.

Na Figura 3, apresenta-se o gráfico de dispersão para a análise da Matriz de Importância versus Desempenho para os atributos pesquisados no curso de Administração. Destaca-se que não foram encontrados atributos nos Quadrantes III e IV. 
Oportunidades de melhoria na disciplina de Contabilidade Introdutória com a utilização do modelo Kano e da matriz de importância versus desempenho

Figura 3 - Gráfico da Matriz de Importância versus Desempenho do curso de Administração

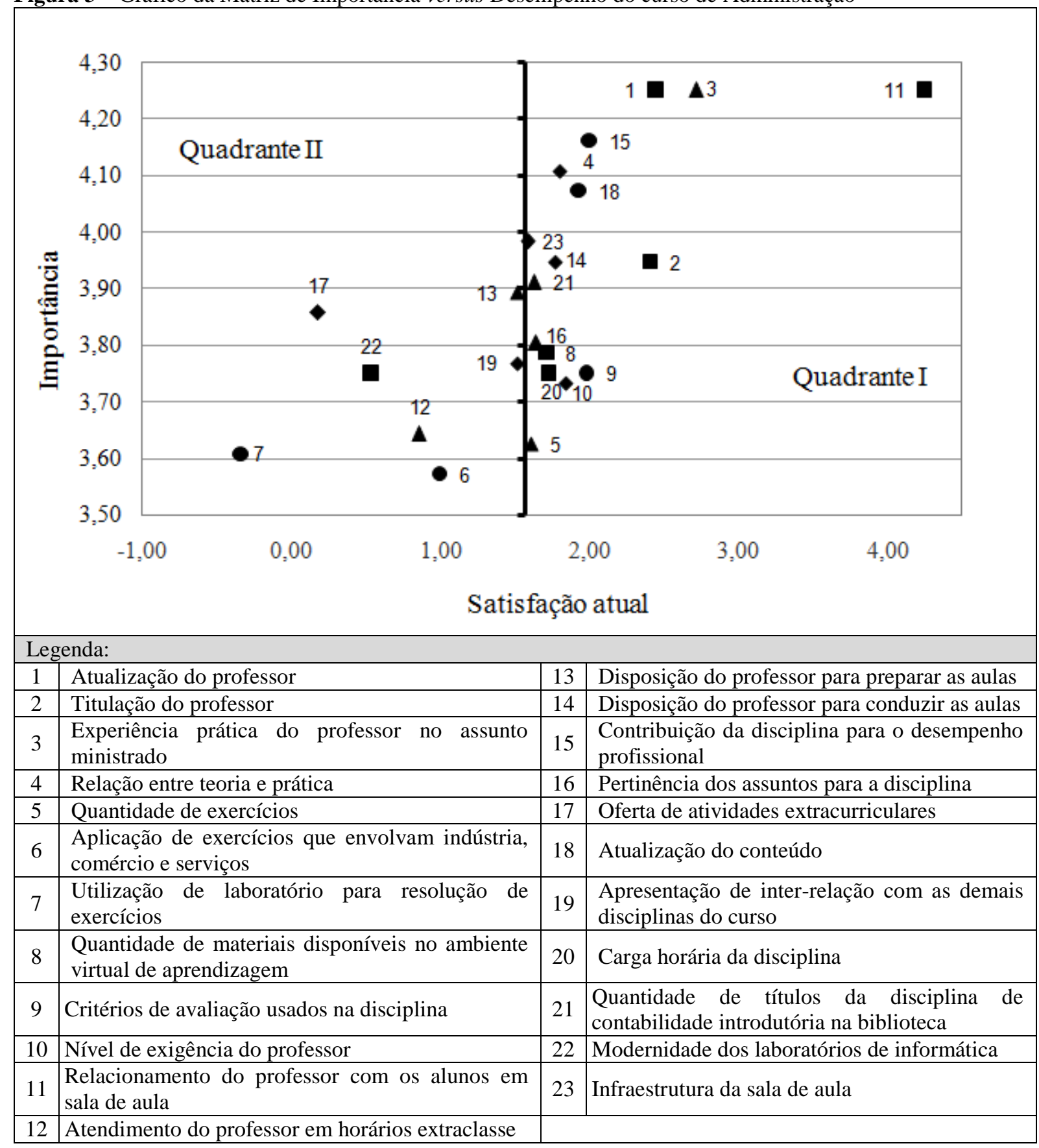

Fonte: os autores.

Os atributos de alta importância e de alta satisfação, ou seja, os pontos fortes da disciplina de Contabilidade Introdutória no curso de Administração, estão demonstrados no Quadrante I da Figura 3: relacionamento do professor com os alunos em sala de aula (11), experiência prática sobre o conteúdo ministrado (3), atualização do professor (1), titulação do professor (2), contribuição da disciplina para o desempenho profissional (15), relação entre teoria e prática na disciplina (4), atualização do conteúdo (18), disposição do professor para conduzir as aulas (14), critérios de avaliação usados na disciplina (9), nível de exigência do 
professor (10), carga horária da disciplina (20) e quantidade de materiais disponíveis no ambiente virtual de aprendizagem (8). Os atributos infraestrutura da sala de aula (23), quantidade de títulos da disciplina na biblioteca (21), pertinência dos assuntos para a disciplina (16) e quantidade de exercícios (5) também se encontram no Quadrante I, contudo muito próximo à média da satisfação atual.

$\mathrm{O}$ atributo de destaque nesse quadrante foi relacionamento do professor com os alunos em sala de aula (11), que se apresenta como o de maior satisfação, igual ao apontado no curso de Ciências Contábeis. Ressalta-se também, que dos 23 atributos analisados, 16 atributos, ou seja, $70 \%$, configuram atributos de alta importância com alta satisfação (Quadrante I).

No Quadrante II, encontram-se os atributos considerados de alta importância e com o nível de satisfação abaixo da média. Foram classificados os 7 atributos restantes, ou seja, 30\%, sendo: oferta de atividades extracurriculares (17), contribuição da modernidade dos laboratórios de informática para a disciplina (22), utilização de laboratório para resolução de exercícios em planilhas eletrônicas (7), aplicação de exercícios que envolvam indústria, comércio e serviços (6), atendimento do professor em horários extraclasse (12). Reforça-se que esses são os atributos que, segundo a Matriz de Importância versus Desempenho, merecem melhorias. Os atributos disposição do professor para preparar as aulas (13) e apresentação de inter-relação com as demais disciplinas do curso (19) estão situados no Quadrante II, porém muito próximos à média da satisfação. $\mathrm{O}$ atributo utilização de laboratórios para resolução de exercícios (7) é o que apresenta a satisfação atual mais baixa.

Da mesma forma que a avaliação feita da disciplina no curso de Ciências Contábeis, nos Quadrantes III e IV, não foram encontrados atributos conforme demonstrado na Figura 3, o que destaca que também para o curso de Administração nenhum dos atributos pesquisados são considerados pelos alunos como de baixa importância.

$\mathrm{Na}$ sequência, demonstra-se na Figura 4 o gráfico de dispersão para a análise do índice de satisfação dos alunos conforme o Modelo Kano de Qualidade Atrativa e Obrigatória. 
Figura 4 - Gráfico do índice de satisfação dos alunos do curso de Administração

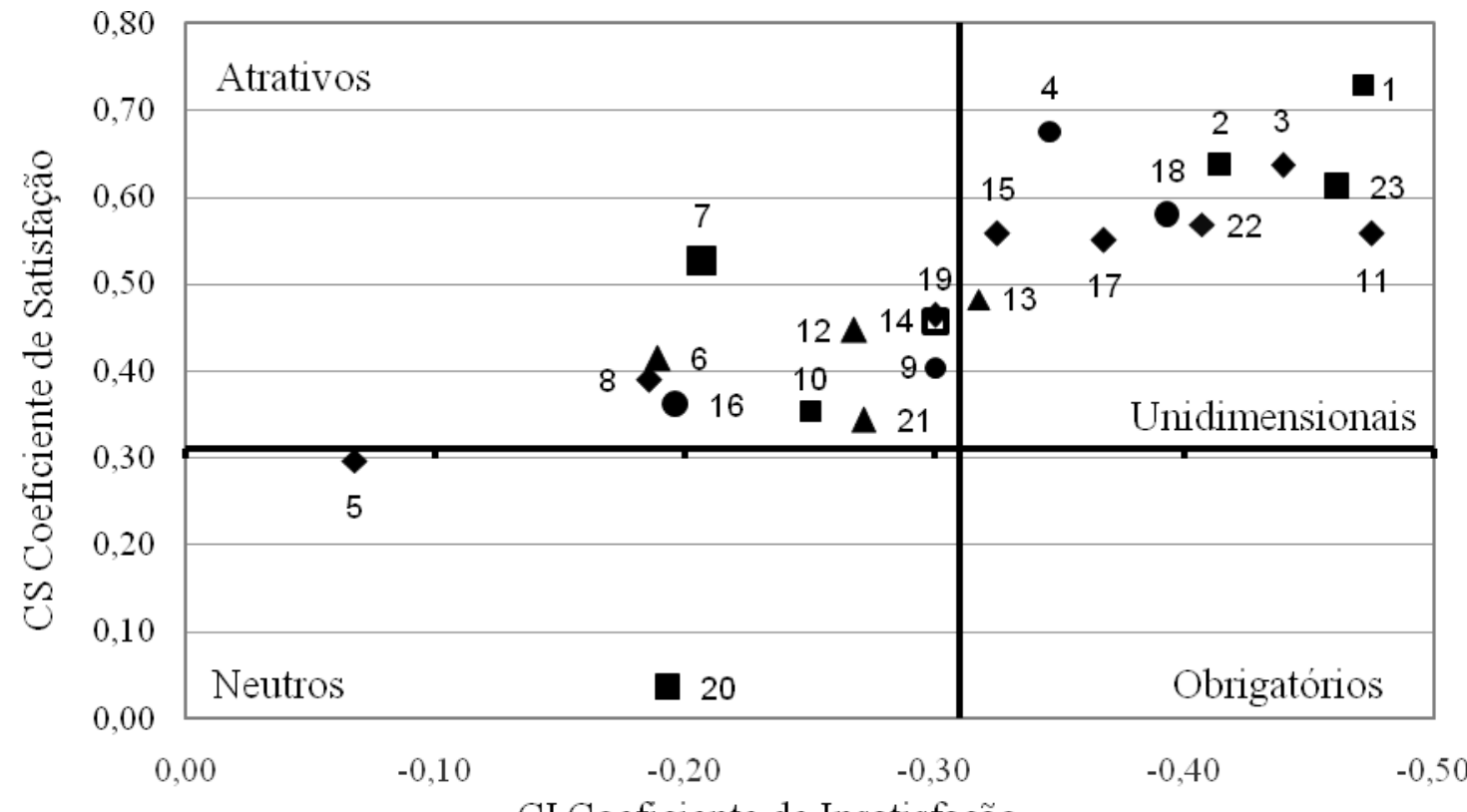

CI Coeficiente de Insatisfação

\section{Legenda:}

$1 \quad$ Atualização do professor $\quad 13$ Disposição do professor para preparar as aulas

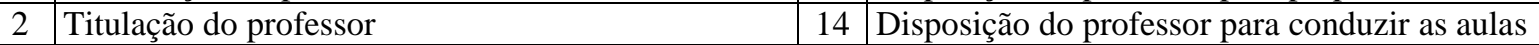

3 Experiência prática do professor no assunto 15 Contribuição da disciplina para o desempenho $3 \begin{aligned} & \text { ministrado } \\ & \text { Relaçã entre teoria e prática }\end{aligned}$

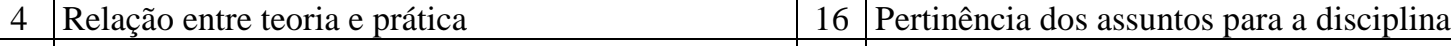

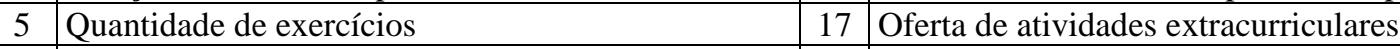

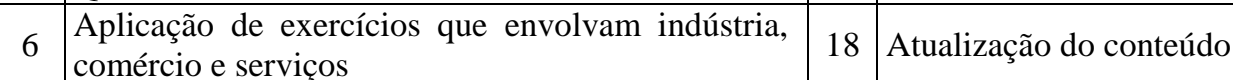

7 Utilização de laboratório para resolução de 19 Apresentação de inter-relação com as demais

\begin{tabular}{l|l|l} 
exercícios & 19 & $\begin{array}{l}\text { Apresentação de inter } \\
\text { disciplinas do curso }\end{array}$ \\
\hline
\end{tabular}

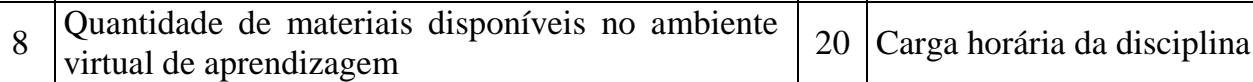

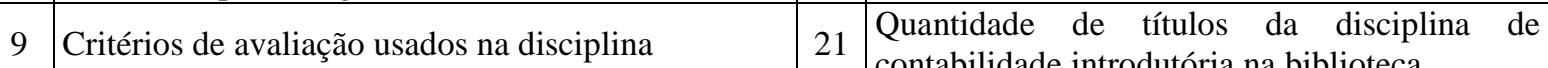

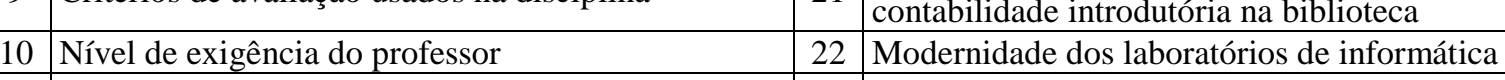

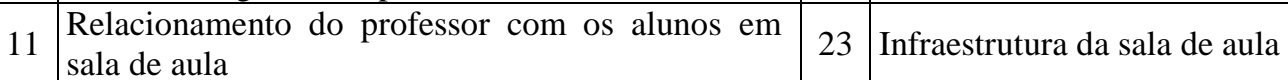

12 Atendimento do professor em horários extraclasse

Fonte: os autores.

A Figura 4 demonstra que dois atributos são considerados como neutros pelos alunos do curso de Administração: carga horária da disciplina (20) e quantidade de exercícios (5). Esse último se apresenta muito próximo da divisão com o quadrante de atributos atrativos.
Entre os atributos classificados como unidimensionais tem-se: atualização do professor (1), infraestrutura da sala de aula (23), relacionamento do professor com os alunos em sala de aula (11), experiência prática sobre o conteúdo ministrado (3), titulação do professor (2), contribuição da modernidade dos 
laboratórios de informática para a disciplina (22), atualização do conteúdo (18), relação entre teoria e prática na disciplina (4), oferta de atividades extracurriculares (17), disposição do professor para preparar as aulas (13) e contribuição da disciplina para o desempenho profissional (15).

Os atributos considerados como atrativos são: apresentação de inter-relação com as demais disciplinas do curso (19), disposição do professor para conduzir as aulas (14), critérios de avaliação usados na disciplina (9), atendimento do professor em horários extraclasse (12), nível de exigência do professor (10), quantidade de títulos da disciplina na biblioteca (21), utilização de laboratório para resolução de exercícios em planilhas eletrônicas (7), aplicação de exercícios que envolvam indústria, comércio e serviços (6), quantidade de materiais disponíveis no ambiente virtual de aprendizagem (8) e pertinência dos assuntos para a disciplina (16).

Identificada a classificação de cada atributo, é possível realizar a análise conjunta dos resultados obtidos para a Matriz de Importância versus Desempenho e para o Modelo Kano. Foram identificados dois atributos como neutros: quantidade de exercícios (5) e carga horária da disciplina (20). Esses atributos não causam satisfação nem insatisfação se tiverem seus desempenhos alterados, ou seja, não se constituem num ponto de atenção de mudança.

Atenção especial deve ser direcionada aos atributos unidimensionais com alta importância e abaixo da média de satisfação, ou seja, apresentam-se simultaneamente no Quadrante II da Matriz de Importância e Desempenho e com atributos unidimensionais no modelo Kano de Qualidade Atrativa e Obrigatória. Nesse aspecto, identificam-se dois atributos: oferta de atividades extracurriculares (17) e modernidade dos laboratórios de informática (22). Observase que um atributo relaciona-se com infraestrutura em relação aos laboratórios, que está fora da alçada do professor e com necessidades de investimento por parte da instituição analisada. Como já apontado na análise do curso de Ciências Contábeis, esse atributo pode ter sido mencionado pelo fato de os alunos não estarem usando com frequência os laboratórios. Além disso, o atributo também foi identificado entre as prioridades de melhoria no estudo de Walter, Tontini e Domingues (2005). O atributo oferta de atividades extracurriculares, por sua vez, integra a categoria conteúdo e foi apontado por Alves (2000) como de alto impacto na qualidade percebida.

Em uma escala de prioridades, em uma segunda etapa, indica-se investir nos 
atributos atrativos, considerados importantes e abaixo da média de satisfação na Matriz de Importância e Desempenho, visto que sua melhoria trará satisfação mais que proporcional, apesar de o baixo desempenho não causar insatisfação: apresentação de inter-relação com as demais disciplinas do curso (19), atendimento do professor em horários extraclasse (12), utilização de laboratório para resolução de exercícios em planilhas eletrônicas (7) e aplicação de exercícios que envolvam indústria, comércio e serviços (6).

\section{CONSIDERAÇÕES FINAIS}

A pesquisa teve por objetivo verificar as oportunidades de melhoria da disciplina de Contabilidade Introdutória nos cursos de Ciências Contábeis e Administração, advindas da análise conjunta da Matriz de Importância versus Desempenho e do Modelo Kano.

Os resultados do estudo mostraram que os atributos considerados prioridades de melhoria no curso de Ciências Contábeis são: utilização de laboratório para resolução de exercícios; modernidade dos laboratórios de informática e a infraestrutura da sala de aula. No curso de Administração, os atributos são: oferta de atividades extracurriculares e modernidade dos laboratórios de informática. Nesse sentido, verificou-se que a estrutura de laboratórios de informática é a mesma para os dois cursos. Observou-se também que, apesar de serem salas diferentes nas turmas, elas apresentam condições estruturais similares (localização, espaço físico, mobiliário, climatização e equipamentos). No entanto, os professores que lecionam essa disciplina nos dois cursos são diferentes.

Ao integrar os resultados obtidos para os dois cursos, chegou-se no atributo modernidade dos laboratórios de informática, que se mostrou como prioridade de melhoria na disciplina de Contabilidade Introdutória.

Como pontos fortes da disciplina, identificaram-se: relacionamento do professor com os alunos, experiência prática do professor no assunto ministrado, atualização do professor, contribuição da disciplina para o desempenho profissional, atualização do conteúdo, titulação do professor, relação entre teoria e prática, disposição do professor para conduzir as aulas, critérios de avaliação usados na disciplina e nível de exigência do professor.

Dessa forma, concluiu-se que a aplicação do Modelo Kano de qualidade aplicado em conjunto com a Matriz de Importância versus Desempenho permitiu uma visualização dos atributos pertinentes à disciplina de Contabilidade Introdutória que devem ser melhorados para 
proporcionar satisfação aos alunos, dentro de uma perspectiva de atributos considerados obrigatórios, unidimensionais, neutros e atrativos.

Espera-se que este estudo possa contribuir para a área de conhecimento por meio da apresentação de uma avaliação da qualidade de uma disciplina de ensino superior, enfoque pouco explorado na literatura, bem como de uma metodologia de análise que permita identificar as prioridades de melhoria. Isso pode ser útil para que as IES implantem e aperfeiçoem seus sistemas de avaliação de disciplinas.

Como limitação da pesquisa, podese mencionar que os dados não podem ser generalizados. Sugere-se para futuras pesquisas a reaplicação do instrumento em novas turmas para comparar com os resultados obtidos neste artigo, visto que os resultados indicam necessidades de investimento por parte da instituição. Também é oportuno averiguar os atributos de qualidade de melhoria dos cursos superiores em outras IES do Vale do Itajaí que tenham a disciplina de Contabilidade Introdutória em sua matriz curricular.

\section{AGRADECIMENTOS}

Trabalho elaborado com auxílio do Edital CNPQ Universal 14/2011.

\section{PREMIAÇÕES}

Artigo Premiado como Melhor Artigo Científico no ANPCONT 2011 na área de Pesquisa e Ensino em Contabilidade.

\section{REFERÊNCIAS}

ALVES, Helena M. B. As dimensões da qualidade no serviço Educação. Revista Portuguesa de Gestão, p. 78-89, out. 2000.

ALVES, Helena M. B.; RAPOSO, Mário. O Marketing nas universidades: um estudo exploratório sobre a satisfação dos alunos como clientes no ensino superior. Revista Portuguesa de Marketing, v. 3, n. 8, p. 67-80, 1999.

BERGER, Charles; BLAUTH, Robert; BOLSTER, Christopher; BURCHILL, Gary; DUMOUCHEL, William; POULIOT, Fred; RICHTER, Reinhart; RUBINOFF, Allan; SHEN, Diane; TIMKO, Mike; WALDEN, David. Kano's methods for understanding customerdefined quality. The Center for Quality Management Journal, v. 2, n. 4, p. 3 36, 1993.

GARVER, Michael S. Best practices in identifying customer-driven improvement opportunities. Industrial Marketing Management, v. 32, p. 455-466, 2003.

KANO, Noriaki. Attractive quality vs must be quality. Journal of the Japanese Society for Quality Control, v. 14, n. 2, p. 39-48, 1984.

MARKS, Ronald B. Determinants of student evaluations of global measures of instructor and course value. Journal of Marketing Education, Thousand Oaks, v. 22, n. 2, p. $108-119$, aug. 2000. 
MARTILLA, John A.; JAMES, John C. Importance-performance analysis. Journal of Marketing, n. 9, p. 41-77, 1977.

MATZLER, Kurt; BAILOM, Franz; HINTERHUBER, Hans H.; RENZI, Birgit; PICHLER, Johann. The asymmetric relationship between attribute-level performance and overall customer satisfaction: a reconsideration of the importance-performance analysis. Industrial marketing Management. v. 33, p. 271-277, 2004.

OWLIA, Mohammad S.; ASPINWALL, Elaine M. A framework for the dimensions of quality in higher education. Quality Assurance in Education, v. 4, n. 2, p. 12120, 1996.

PARASURAMAN, A.; ZEITHAML Valarie A.; BERRY Leonard L. SERVQUAL: A multiple-item scale for measuring consumer perceptions of service quality, Journal of Retailing, v. 64, n. 1, p. 12-40, 1988.

PELEIAS, Ivan R. Didática do ensino da contabilidade: aplicável a outros cursos superiores. São Paulo: Saraiva, 2006.

RAUPP, F. M.; BEUREN, I. M.

Metodologia da pesquisa aplicável às ciências sociais. In: BEUREN, Ilse Maria (Org. e Colab.). Como elaborar trabalhos monográficos em contabilidade: teoria e prática. 2 ed. São Paulo: Atlas, 2004.

SILVEIRA, Amélia; APPIO, Jucélia; DOMINGUES, Maria J. C. de S. Atributos de qualidade da disciplina de custos aplicados à administração. In.

CONGRESSO BRASILEIRO DE CUSTOS, 15., 2008. Curitiba. Anais... Curitiba: ABC, 2008.

TONTINI, Gérson. Administração estratégica da qualidade: a chave para a produtividade e a competência. Revista de Negócios, Blumenau, v. 1, n. 3, p. 5-12, 1996.
TONTINI, Gérson. Como identificar atributos atrativos e obrigatórios para o consumidor. Revista de Negócios, Blumenau, v. 8, n. 1, p. 19-27, 2003.

TONTINI, Gérson; SILVEIRA, Amélia. Identification of critical attributes of success in products and services: an alternative to importance-performance analysis. In: BUSINESS ASSOCIATION OF LATIN AMERICAN STUDIES, Madrid. Proceedings... Madrid: BALAS, 2005 .

WALTER, Silvana A. Antecedentes da satisfação e da lealdade de alunos de uma instituição de ensino superior. 2006. 167 f. Dissertação (Mestrado em Administração) - Programa de PósGraduação em Administração, Centro de Ciências Sociais Aplicadas, Universidade Regional de Blumenau, Blumenau, 2006.

WALTER, Silvana A.; TONTINI, Gérson; DOMINGUES, Maria J. C. de S. Identificando oportunidades de melhoria em um curso superior através da análise da satisfação dos alunos. In: ENCONTRO DA ASSOCIAÇÃO NACIONAL DOS PROGRAMAS DE PÓS-GRADUAÇÃO EM ADMINISTRAÇÃO, 29., 2005, Brasília. Anais... Rio de Janeiro: ANPAD, 2005.

\section{ZANCHETT, Ricardo. Serviços} logísticos: influência dos diferentes atributos de qualidade na satisfação e na lealdade dos clientes. 2009. 113f. Dissertação (Mestrado em Administração) - Programa de Pós-Graduação em Administração, Centro de Ciências Sociais Aplicadas, Universidade Regional de Blumenau, Blumenau, 2009. 